\title{
Technology and Creativity on early adolescence: A case study during COVID-19 pandemic
}

\author{
Spyros Kolyvas $^{1}$ (D) Stefanos Nikiforos ${ }^{2}$ (D)
}

Accepted: 28 September 2021

(c) The Author(s), under exclusive licence to Springer Science+Business Media, LLC, part of Springer Nature 2021

\begin{abstract}
Distance education was imposed due to the sudden suspension of schools as a result of the COVID-19 pandemic. Impact of technology use on distance learning in early adolescence was the main aim of the current research. Asynchronous teaching methods were implemented in a digital classroom environment during the COVID-19 pandemic. Teaching practice was enriched with the use of technology-based tools. Results revealed that such a teaching practice method could have a positive impact on students' creativity, increasing their motivation to create and develop new forms of social interaction. Students who did not actively participate in face to face educational process, took an active participating role during distance education. This research is regarded as original, as it concerns a case study of asynchronous teaching during the first period of the COVID-19 pandemic.
\end{abstract}

Keywords Technology $\cdot$ Creativity $\cdot$ Early adolescence $\cdot$ COVID-19 pandemic $\cdot$ Technology-based tools $\cdot$ Distance learning

Distance education in Greece did not emerge as a result of a plan, but it was imposed as Emergency Remote Teaching (ERT) (Hodges et al., 2020), due to the sudden suspension of school operation during the COVID-19 pandemic. Schools, teachers and parents were neither prepared, nor trained to handle the complexity and the demands of ERT (Black et al., 2021). Providing effective e-learning proved to be a challenge. Teachers had limited resources, while students had to adapt to a new teaching situation, based in many cases on teacher to student interaction. Opportunities for direct interaction with classmates were limited (Espino-Díaz et al., 2020).

Social problems in the field of education, as well as issues of inability of vulnerable social groups to access distance education arose during the first phase of the COVID-19 pandemic. These issues should be investigated in order to ensure

Stefanos Nikiforos

nikiforos@ionio.gr

Spyros Kolyvas

119koly27@ionio.gr

1 Department of Archives, Library Science and Museology, Ionian University, Ioanni Theotoki 72, 49100 Corfu, Greece

2 Humanistic and Social Informatics Laboratory(HILab), Department of Informatics, Ionian University, 7 Tsirigoti square, $49100 \mathrm{Corfu}$, Greece equal participation of all the students in the learning process. Indiscriminate use of technology contributes to the widening of social inequalities. Due to the existing educational inequalities that mainly affect vulnerable social groups, as well as due to the need to socialize students, pediatricians suggested return of the students to schools as soon as possible (American Academy of Pediatrics, 2020). Survey results showed that adolescents were very concerned about the COVID-19 crisis and they were particularly concerned of school attendance and peer relationships (American Academy of Pediatrics, 2020). COVID-19 anxiety is associated with more loneliness and more depression, especially for teens who spend more time on social media (Magson et al., 2021). At the same time, family time and schoolwork are negatively associated to depression. Online support for adolescents with depressive symptoms, is considered as important. Research results provided promising ways to prevent loneliness, as time with family, time with friends and physical activity were associated with lower loneliness, in addition to COVID-19 stress (Ellis et al., 2020). 


\section{Related Work}

Introduction of new technologies, such as digital classrooms and web-based collaborative tools in particular, have created new avenues and ways of working, for both the teachers and the students. While real-life course practices depend primarily on face to face interactions among the teachers and the students, interaction through digital environments has enabled application of innovative practices and the establishment of Virtual Learning Communities (VLCs). Teachers through the digital environment have the opportunity to interact with their students in ways that enhance students' socially constructed knowledge, learning and creativity (Dillenbourg et al., 2009; Innes, 2007; Knipfer et al., 2009; Rovai, 2002; Stahl et al., 2006; Wells, 2002; Veermans \& Cesareni, 2005). Virtual museum tours, artworks, exhibitions, digital libraries, encyclopedias or digital artifacts are some typical example uses of technology-based tools. Virtual environments expand space and time: creative work through collaborative tasks is usually difficult to be applied in the physical classroom due to lack of time or availability of resources (hardware).

Such a way of teaching, assisted by the use of technology-based tools, could have a positive impact on students' creativity, increasing their motivation to create and develop new forms of social interaction (Brown, 2012; Gauntlett, 2015; Mace \& Ward, 2002).

Concept of creativity is difficult to define by a single definition as there are infinite definitions (Davis, 1992). The basic components that make up the common denominator of creativity are: the creative thinking process, the creative product, and the creative environment (Brown, 1989). Guilford (1950) and Piaget (1960) considered the process of creative thinking as a mental process and linked it to the problem-solving process. Mednick (1962) considered that there is a difference between a truly creative and a simply strange product. A product can be evaluated as creative through the parameters it satisfies. Newell and Simon (1972) believe that creativity can also be seen as the process by which the individuals activate new original ideas, which help them to deal with everyday problems and challenges. Environment plays a very important role in creativity. Encouragement and creating a positive climate are supportive factors for creativity enhancement (Boden, 1999).

Distance learning through the digital classrooms enables teachers to adopt new roles and to shape a studentcentered environment. In this way they are able to develop team dynamics, to design teaching scenarios utilizing technology-based tools facilitating collaborative discovery, shaping and sharing knowledge, which are essential for the development of creativity (Cole, 2009; Wheeler \& Wheeler, 2009). Teacher involvement is a critical factor for the smooth function of a community. It seems to act as a compass, a point of reference, providing a supportive function (Nikiforos et al., 2020). Studies have shown that simulation and collaboration allow learning in an interactive environment (Mnyanyi \& Mbwette, 2009; Thamarana, 2016). Other studies showed that students and parents quickly adapt to distance education (Bubb \& Jones, 2020), resulting in more creative learning, better progress, more helpful feedback and greater student independence (Bubb \& Jones, 2020).

Success of distance education heavily depends on the well designed educational material and not on the medium. In asynchronous distance education teaching the student interacts mainly with the educational material. In this way, quality of the educational material can determine the learning outcome. Although technological means are necessary for accessing the educational material, type of the technological means is not a determining factor. On the contrary, the pedagogical method is the determining factor. Design and development of interactive material, fully comprehensive for the students, is required. Worksheets should contain activities that motivate students to use the appropriate technology-based tools: interactive books, discussion forums and blogs. Interactive applications provide students the opportunity to interact with the projects by visiting virtual museum sites and participating in educational games. Teacher is expected to inspire, to guide and support the student's interaction with the educational material (Nacu et al., 2018).

Teacher training is a major challenge that will enable promotion and creation of new content as well as the use of technological tools based on the pedagogy (Carvalho, 2020). An ongoing dialogue between education and technology is essential. Concerns regarding the curriculum and the way the appropriate digital tools can be integrated to support the pedagogical practice, with respect to the particularities of each subject, need to be analyzed. Digital space must be used pedagogically, in a critical, creative and interdisciplinary manner. Information technologies (ICT) as a supportive tool in education can bring revolutionary changes, when there is a pedagogical approach and qualitative criteria.

Schools during the COVID-19 pandemic had the opportunity to develop students' higher thinking skills with the help of technology (Engerman et al., 2018; Hopson et al., 2001; Nusbaum et al., 2020). High order thinking skills include creative and critical thinking and problem solving (Ramos et al., 2013). Distance education using computers and technology-based tools helped classroom restructure (Hopson et al., 2001). Digital classrooms facilitate active learning, complex problem solving and higher-order thinking skills (Dalton \& Goodrum, 1991). 
Incorporating technology in an active learning environment, students can develop higher-order thinking skills such as analysis, synthesis of ideas, judgments, and application of theories (Barak \& Dori, 2009; Barak \& Levenberg, 2016). Students do not passively accept information, they have the opportunity to construct knowledge. Providing distance education to students using computers and technology-based tools helps classroom restructure. The teacher, through distance learning, using digital applications provides students with active learning, authentic tasks, complex problem solving and higher-order thinking skills (Dalton \& Goodrum, 1991). Learning is more student-focused and less teacherled. Students have the ability of collaborative interaction with their peers. Information is used to stimulate students to focus on hypotheses testing. Students actively manipulate information in a variety of contexts from a number of resources to solving meaningful problems (Dede, 1990; Ramizer \& Bell, 1994).

Digital education in Greece during the first period of the COVID-19 pandemic was mainly asynchronous. Due to the pandemic, there was a need for a sharp and sudden transition to distance education, without the proper preparation and the necessary infrastructure. As a result, asynchronous distance education through digital classrooms was exclusively provided at all levels of education in Greece. The current study was implemented exclusively by asynchronous distance learning methods. Students and teachers did not interact at the same time, but they communicated through digital classrooms, e-mails or blogs. Teaching was mainly based on teaching plans, clear instructions and directions by the teachers, allowing learning to happen anytime and anywhere (Molnar et al., 2019). Main aim of the study was to investigate the impact of technology-based tools use on early adolescence students' creativity during distance learning implementation in the covid-19 pandemic.

\section{Methods}

\section{Background of the Study}

A case study in K-12 education took place in the spring semester of 2020, during the COVID-19 pandemic. Schools were closed and the teaching process took place through the digital classroom (e-class) asynchronous tool. The study involved 22 ( 8 boys and 14 girls) K-12 students of early adolescence (age 12). Learning activities took place for 10 weeks. Students were provided with specially designed worksheets, containing detailed instructions and directions, adapted to the class level and to the goals of each teaching unit. Two teachers participated actively in the project. Through the worksheets, students were assigned tasks to create artifacts, using either technology-based tools or traditional tools (tempera, watercolors, colored pencils, papers, recyclable materials) (Sawyer, 2011; Zhang \& Sternberg, 2011). Some activities were implemented using traditional tools, while others with technology-based tools use. In this way, each student used both traditional and technology-based tools. A comparison of technology-based and traditional tools was made in order to highlight the technology influence.

\section{The Study Process}

Four teaching modules were implemented during the project: shape in art, express my feelings with color, virtual museum tour and Byzantine art. Technology-based tools included virtual museum tours and art works through the Google arts \& culture (https://artsandculture.google.com/) and Photodentro (http://photodentro.edu.gr/aggregator/) online platforms. Students also used Wikipedia (https://el. wikipedia.org/), for information search. Digital artworks were created with the Canvas Paint software (https://canvas. apps.chrome/). Photo editing and artwork variations were created through Photomosh (https://photomosh.com/) and Chromata (https://www.michaelbromley.co.uk/experiments/ chromata/). Photo puzzles were also created with Jigsawplanet (https://www.jigsawplanet.com/).

Students' activities were guided through worksheets. Teachers uploaded the worksheets in the digital classroom and notified the students accordingly via announcements. Worksheets contained information regarding the topic of the course, the teaching objectives, as well as detailed instructions for the process to be followed. Course topics were interdisciplinary as they concerned ICT, history, art and religious education. Tools needed were described in detail. Hyperlinks for websites, material sources, digital museums and technology-based tools were provided to the students. Each worksheet also contained an entertaining educational activity.

Digital environment provided the ability of asynchronous communication among the community members: discussion with peers, clarifications, question answering. Once the process was completed, students posted their assignments (artifacts) in the digital classroom environment and they received feedback and reward by the teacher and their peers. In this way, artifacts were presented in the digital environment, facilitating the interaction among the community members (Botella et al., 2013). Students, taking into account the community members' comments, had the ability to return to an earlier stage of the creative process, in order to reconstruct some parts of their work (Tinio, 2013). As a result, artifacts consisted a community creation, since the digital forum provided a community creation framework through the interaction among the members. 
In this study, creativity was analyzed through the amount of the artifacts created, their level of completion, the actions and interaction within the VLC, the interest, the participation, as well as the time and duration of engagement (Pelowski et al., 2017).

\section{Analysis Methods}

Research data were collected through the log files of the digital educational platform. Two annotators contributed on the data analysis. The number of the annotators was determined by the Spearman-Brown reliability calculation (Nunnally, 1967). Students' participation in the project was evaluated through (a) the submission of their assignments and (b) the interaction developed through their dialogues. Artifacts were evaluated on a 20-point scale regarding their relevance to the subject, the use of technology-based tools, the originality of the artifacts, the obvious effort, the variety of shapes, the detail, the complexity, the perfection and the process followed according to the directions in the worksheet in order to create the artifacts (Amabile, 1982). Relevance to the subject refers to the correspondence of artifacts to the respective worksheet topic. Use of technology-based tools was evaluated throughout the creative process: searching for information, collecting material, creating artifacts. Originality of the artifacts refers to the creative and original solutions developed by the students during the creative process. Obvious effort was evaluated through the proposed solutions, use of tools, as well as the details and the perfection of the artifacts. The learning effort made by the students is considered as an important condition for their academic results. Research has shown a strong correlation between the learning effort and the academic outcomes (Rau \& Durand, 2000; Rodgers, 2008).

Variety of shapes, details and complexity of artifacts (shapes, colors, contrasts) were also evaluated. The creating process was evaluated, taking into account whether the students followed the worksheet instructions, while perfection of the artifacts was measured based on all the above mentioned indicators. An artifact was characterized as even, provided that the effort made to follow worksheet instructions, in order to complete it and reach the desired result, was obvious. Content of the artifact should correspond to the topic of the worksheet activity. It should also be original, i.e. the student during the creative process developed original solutions in terms of the composition of the morphological elements (shape, color, tone, line), in order to respond in a personal way to the demands of the educational activity. It should be evident from the image of the artifact that the student had followed all the stages of the creative process, as described in the worksheet and that attention had been paid to detail and finishing.
Two annotators, one teacher and one art teacher having many years of experience in the respective educational level, evaluated the artifacts relatively to each other, using the most complete as a means of comparison, instead of rating them with any absolute standards. According to Amabile (1982), it is possible to obtain reliable judgments of creativity, given an appropriate group of annotators. By definition, inter-annotator credibility is equivalent to construct validity. Assessments of the annotators were also used to determine whether the worksheet activities were appropriate for the distance learning purposes.

Descriptive and inductive statistics were used for the statistical processing of data. Statistical analysis concerned students' artifacts evaluation. In the first stage, a descriptive statistical analysis of the data was performed, presenting frequencies, percentages, as well as the position of one value in relation to the others (Creswell, 2011; Papanastasiou, \& Papanastasiou, 2021). Correlation between the independent variables of a) gender and b) digital-handmade artifacts with the quantitative variables of: i) relevance to the subject, ii) use of tools, iii) originality, iv) effort, v) variety of shapes, vi) details, vii) complexity and viii) perfection, was examined through using t-test (comparison between two groups for independent samples) (Papanastasiou, \& Papanastasiou, 2021; Roussos \& Tsaousis, 2011). Pearson $r$ statistical test was selected for the correlations analysis between the variables: i) use of technology-based tools with perfection of artifacts, ii) obvious effort with perfection of artifacts, iii) process with perfection of artifacts, iv) process with artifacts related to the subject, v) originality of artifacts with technology-based tools use, vi) use of technology-based tools with complexity of artifacts, as the regularity test revealed that all cases followed normal distribution (Roussos \& Tsaousis, 2011).

\section{Results}

The average correlation between the annotators was high, contributing to the inter-annotator reliability (Amabile, 1982). A statistical t-test was performed in order to examine possible significant differences regarding the gender of the students. Results showed that there were no statistical significant differences between the boys' and the girls' artifacts. However, it should be noted that the sample of boys' artifacts was small. Average value of artifacts, created exclusively with technology-based tools was higher (16.9) than the average value (15.6) of handmade artifacts (Fig. 1).

The highest values of creativity variables were recorded in the relevance (17.8) and the process (16.8) indicators (Fig. 2). Use of technology-based tools was also evaluated as high (15.8). The lowest values were observed in the detail (14.6) and complexity indicators (14.6). Average indicators' 
Fig. 1 Average values regarding digital and handmade artifacts

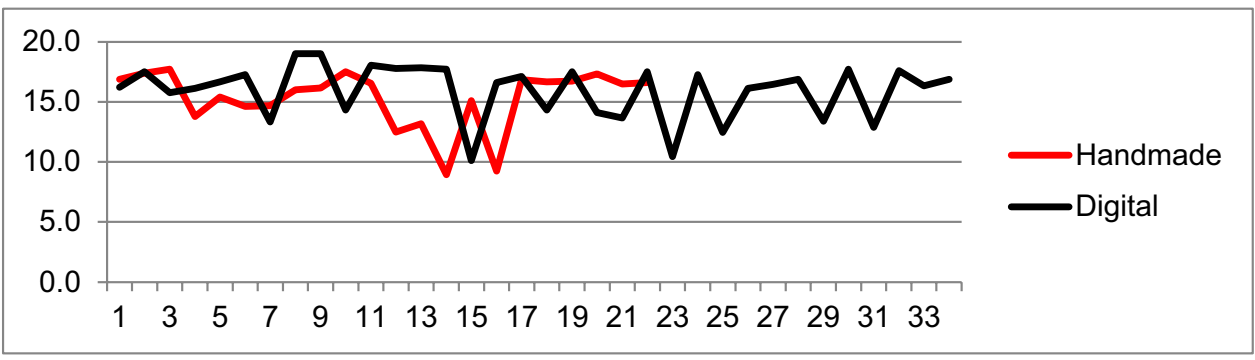

Fig. 2 Average values of creativity variables

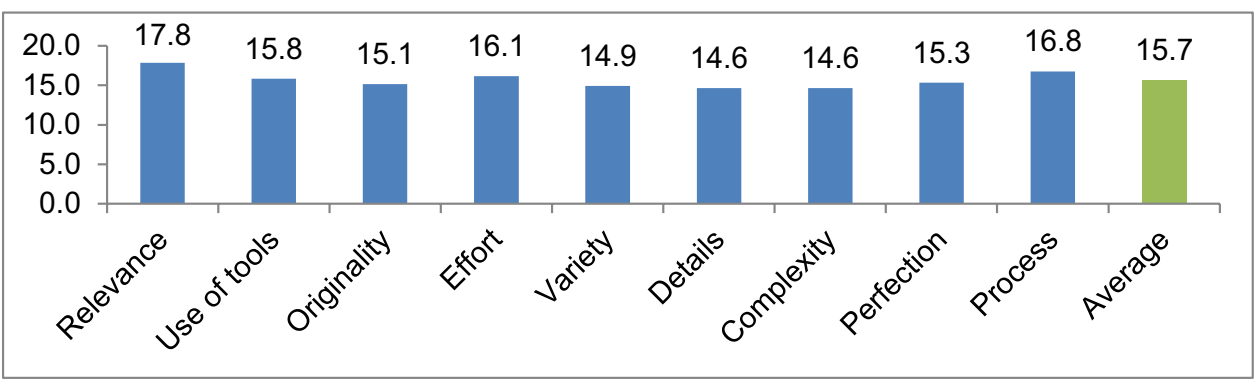

rate shows that the students responded positively to the objectives of distance learning. These results reveal the students' quick adjustment to the new educational situation: use of technology-based media during COVID-19 pandemic. Due to the sudden transition to distance learning there was no possibility of pre-test research, creating restrictions on the generalization of the research.

High average evaluation regarding i) the use of technology-based tools (15.8) and ii) the artifacts created exclusively with technology-based tools (16.9) underlines this adjustment. High average score of the nine indicators (15.7) also reveals that the worksheets met the students' needs and helped them to successfully respond to all the activities of the learning process. Application of t-test statistical criterion revealed that there were no statistical significant differences between any of these nine indicators.

Pearson $r$ correlation coefficient was also calculated in order to find out whether the indicators were correlated with each other. As a first step, it was confirmed through the study of scatter diagrams that the correlation of variables was linear. Data analysis revealed that there was a statistically significant strong positive correlation between the use of technology-based tools and the perfection of the artifacts $(r(54)=0.72, p<001)$. More specifically, as the use of technology-based tools increases, perfection of the artifacts is improved. Obvious effort and perfection of the artifacts are also strongly positively correlated $(r(54)=0.845, p<0.001)$. Once the obvious effort increases results in the improvement of the artifacts' perfection. Following the process provided by the instruction sheets affected positively the quality of the artifacts. Strong positive correlation was observed between these two indicators (process and perfection) $(r(54)=0.692$, $p<0.001)$. Originality of the artifacts appeared to be highly strongly correlated with the use of technology-based tools $(r(54)=0.807, p<0.001)$. As it was expected, following the process resulted in creation of artifacts more relevant to the subject $(r(54)=0.793, p<0.001)$. Finally, use of technologybased tools was found to be highly positively correlated with both the complexity of the artifacts $(r(54)=0.673, p<0.001)$ and the objects variety $(r(54)=0.653, p<0.001)$.

\section{Discussion}

Analysis of the results revealed that the students who participated in the digital classroom environment, during the COVID-19 pandemic, were able to successfully respond to distance education needs and make proper use of the technology-based tools. This fact acquires a special value, taking into account the sudden imposition of distance education and the lack of i) training for the teachers, ii) educational material, iii) psychological support and iv) infrastructure. High values of all the individual creativity indicators confirm students' adaptation to the new educational circumstances. ICT technologies, as a supportive tool in education, can bring about revolutionary changes when there is a pedagogical approach and qualitative criteria (Livingstone, 2012). Schools during the COVID-19 pandemic had the opportunity, with the help of technology, to develop higherorder thinking skills for the students (Dalton \& Goodrum, 1991; Dede, 1990; Engerman et al., 2018; Nusbaum et al., 2020; Ramizer \& Bell, 1994).

A significant percentage of students did not attend the digital classrooms during the first lockdown of the 
COVID-19 pandemic. This was due to the non-compulsory participation for the students, as well as due to the lack of infrastructure and digital education, especially for families who belong to vulnerable social groups (Black et al., 2021). Out of a total of 22 students, 5 students had occasional participation in the learning process, a fact that seemed to have an effect on their overall learning performance.

Average score of the 9-dimensional evaluation of students' artifacts showed that there were no significant differences between boys and girls in terms of the outcome of activities and the achievement of learning objectives. However, it should be noted that participation of the boys in the digital classroom was small.

It was also observed that use of technology (technologybased tools) helped the students to create artifacts of higher quality comparing to the handmade ones. This was probably due to the familiarity of students with some digital tools during face to face teaching, as well as due to the proper structure and guidance provided by the worksheets to the students. This can be seen from the high score on the worksheet process indicator. Use of tools, such as virtual museum tours and platforms, also acted as a boost in student activity. Continuous and thorough feedback provided by the teacher to the students, in order to support and encourage their participation in the learning process played an important role (Christensen et al., 2008; Molnar et al., 2019; Nacu et al., 2018). Students enrolled in the digital classroom showed interest and participated actively throughout the quarantine period. This was might due to the worksheets being designed to attract students' interest, to include interaction and the element of discovery (Ferrari et al., 2009). Worksheets included visual material, correct and detailed guidance, a variety of digital tools, interactive learning activities and educational games which motivated students to make an even greater effort.

A significant correlation between the perfection of the artifacts and the use of technology-based tools was observed. Use of technology can contribute to the perfection of the artifacts (Engerman et al., 2018; Nusbaum et al., 2020). Analysis of the data also showed that the 'faithful' following of the process, the working steps described in the worksheets, was correlated with the perfection of the artifacts. An important correlation was also observed between the use of technology-based tools with both the originality of the artifacts and their relevance to the subject. Proper implementation of the process contributed to the relevance of the artifacts to the subject.

Analysis of the digital classroom log files revealed that the students devoted much more time in the digital environment, comparing to the duration (45 $\mathrm{min}$ ) of face to face teaching. This was probably due to the learning process based mainly on the teaching plans and the clear instructions and directions of the teachers, allowing learning anytime and anywhere (Molnar et al., 2019).

\section{Conclusions}

The current teaching proposal expanded the physical space and removed any time limits. It overcame obstacles such as lack of the infrastructure and encouraged experimentation through the use of technology-based tools. Therefore, it is suggested that this teaching proposal can increase the students' interest and facilitate the lesson objectives. Primary research on student participation, use of digital tools and student objects revealed that technology-based tools use had a positive impact on students' creativity, increasing their motivation to create and develop new forms of social interaction (Brown, 2012; Gauntlett, 2015; Mace \& Ward, 2002). However, the ability to generalize conclusions is limited due to the small sample. Further studies are needed to draw robust conclusions.

Data Availability The datasets generated during and/or analysed during the current study are not publicly available due to containing information that could compromise research participant privacy/consent, but are available from the corresponding author on reasonable request.

\section{Declarations}

Ethical Approval All procedures performed in studies involving human participants were in accordance with the ethical standards of the institutional and/or national research committee and with the 1964 Helsinki declaration and its later amendments or comparable ethical standards. This article does not contain any studies with animals performed by any of the authors.

Informed Consent Informed consent was obtained from all individual participants included in the study.

Conflict of Interest The authors have no conflicts of interest to declare that are relevant to the content of this article.

\section{References}

Amabile, T. M. (1982). Social psychology of creativity: A consensual assessment technique. Journal of Personality and Social Psychology, 43(5), 997. https://doi.org/10.1037/0022-3514.43.5.997

American Academy of Pediatrics. Covid-19 planning considerations: quittance for school re-entry. Critical Updates on COVID-19. Published June 25, 2020. https://services.aap.org/en/pages/2019novel-coronavirus-covid-19-infections/clinical-guidance/covid19-planning-considerations-return-to-in-person-education-inschools/. Accessed 13 Jul 2020.

Barak, M., \& Dori, Y. J. (2009). Enhancing higher order thinking skills among in service science teachers via embedded assessment. Journal of Science Teacher Education, 20(5), 459-474. https:// doi.org/10.1007/s10972-009-9141-z 
Barak, M., \& Levenberg, A. (2016). Flexible thinking in learning: An individual differences measure for learning in technologyenhanced environments. Computers \& Education., 99, 39-52. https://doi.org/10.1016/j.compedu.2016.04.003

Black, E., Ferdig, R., \& Thompson, L. A. (2021). K-12 virtual schooling, COVID-19, and student success. JAMA Pediatrics, 175(2), 119-120. https://doi.org/10.1001/jamapediatrics.2020.3800

Boden, M. A. (1999). Computer models of creativity. In R. J. Sternberg (Ed.), Handbook of creativity (pp. 351-372). Cambridge University Press.

Botella, M., Glaveanu, V., Zenasni, F., Storme, M., Myszkowski, N., Wolff, M., \& Lubart, T. (2013). How artists create: Creative process and multivariate factors. Learning and Individual Differences, 26, 161-170. https://doi.org/10.1016/j.lindif.2013.02.008

Brown, K. S. (2012). Cohomology of groups (Vol. 87). Springer Science \& Business Media. https://doi.org/10.1007/978-1-4684-9327-6

Brown, R. T. (1989). Creativity: what we are to measure? In E. P. Torrance, J. A. Glover, R. R. Ronning, \& C. R. Reynolds (Eds.), Handbook of creativity. Perspectives on individual differences (pp. 3-32). New York; London: Plenum. https://doi.org/10.1007/ 978-1-4757-5356-1

Bubb, S., \& Jones, M. A. (2020). Learning from the COVID-19 homeschooling experience: Listening to pupils, parents/carers and teachers. Improving Schools, 23(3), 209-222. https://doi.org/10. $1177 / 1365480220958797$

Carvalho, I. (2020). The construction of Digital Teaching Skills: A challenge for Teacher Training. In TEEM'20:Eighth International Conference on Technological Ecosystems for Enhancing Multiculturality (pp. 892-895). https://doi.org/10.1145/3434780.3436663

Christensen, C. M., Horn, M. B., \& Johnson, C. W. (2008). How “disruptive innovation" will change the way we learn. Education Week, 27(39), 25-36.

Cole, M. (2009). Using Wiki technology to support student engagement: Lessons from the trenches. Computers \& Education, 52(1), 141-146. https://doi.org/10.1016/j.compedu.2008.07.003

Creswell, J. W. (2011). Educational research: Planning, conducting, and evaluating quantative and qualitative research. Pearson Education International.

Dalton, D. W., \& Goodrum, D. A. (1991). The effects of computer programming on problem-solving skills and attitudes. Journal of Educational Computing Research, 7(4), 483-506. https://doi.org/ 10.2190/762V-KV6T-D3D1-KDY2

Davis, G. A. (1992). Creativity is forever (3rd ed.). Kendall/Hu.

Dede, C. J. (1990). The evolution of distance learning: Technologymediated interactive learning. Journal of Research on Computing in Education, 22(3), 247-264. https://doi.org/10.1080/08886504. 1990.10781919

Dillenbourg, P., Järvelä, S., \& Fischer, F. (2009). The Evolution of Research on Computer-Supported Collaborative Learning. In N. Balacheff, S. Ludvigsen, T. de Jong, A. Lazonder, \& S. Barnes (Eds.), Technology-Enhanced Learning. Dordrecht: Springer. https://doi.org/10.1007/978-1-4020-9827-7_1

Ellis, W. E., Dumas, T. M., \& Forbes, L. M. (2020). Physically isolated but socially connected: Psychological adjustment and stress among adolescents during the initial COVID-19 crisis. Canadian Journal of Behavioural Science/revue Canadienne Des Sciences Du Comportement, 52(3), 177. https://doi.org/10.1037/cbs00 00215

Engerman, J. A., MacAllan, M., \& Carr-Chellman, A. A. (2018). Games for boys: A qualitative study of experiences with commercial off the shelf gaming. Educational Technology Research and Development, 66(2), 313-339. https://doi.org/10.1007/ s11423-017-9548-8

Espino-Díaz, L., Fernandez-Caminero, G., Hernandez-Lloret, C. M., Gonzalez-Gonzalez, H., \& Alvarez-Castillo, J. L. (2020). Analyzing the impact of COVID-19 on education professionals. toward a paradigm shift: ICT and neuroeducation as a binomial of action. Sustainability, 12(14), 5646. https://doi.org/10.3390/ su12145646

Ferrari, A., Cachia, R., \& Punie, Y. (2009). Innovation and creativity in education and training in the EU member states: Fostering creative learning and supporting innovative teaching. JRC Technical Note, 52374, 64. https://doi.org/10.2791/52913

Gauntlett, D. (2015). The LEGO System as a tool for thinking, creativity, and changing the world. In: Making Media Studies: The Creativity Turn in Media and Communications Studies. Peter Lang.

Guilford, J. P. (1950). Creativity. American Psychologist, 5, 444-454. https://doi.org/10.1037/h0063487

Hodges, C., Moore, S., Lockee, B., Trust, T., \& Bond, A. (2020). The difference between emergency remote teaching and online learning. Educause Review, 27, 1-12.

Hopson, M. H., Simms, R. L., \& Knezek, G. A. (2001). Using a technology-enriched environment to improve higher-order thinking skills. Journal of Research on Technology in Education, 34(2), 109-119. https://doi.org/10.1080/15391523.2001.10782338

Innes, R. B. (2007). Dialogic communication in collaborative problemsolving groups. International Journal for the Scholarship of Teaching and Learning, 1(1), n1. https://doi.org/10.20429/ijsotl. 2007.010104

Knipfer, K., Mayr, E., Zahn, C., Schwan, S., \& Hesse, F. W. (2009). Computer support for knowledge communication in science exhibitions: Novel perspectives from research on collaborative learning. Educational Research Review, 4(3), 196-209. https://doi.org/ 10.1016/j.edurev.2009.06.002

Livingstone, S. (2012). Critical reflections on the benefits of ICT in education. Oxford Review of Education, 38(1), 9-24. https://doi. org/10.1080/03054985.2011.577938

Mace, M. A., \& Ward, T. (2002). Modeling the creative process: A grounded theory analysis of creativity in the domain of art making. Creativity Research Journal, 14(2), 179-192. https://doi.org/ 10.1207/S15326934CRJ1402_5

Magson, N. R., Freeman, J. Y. A., Rapee, R. M., Richardson, C. E., Oar, E. L., \& Fardouly, J. (2021). Risk and Protective Factors for Prospective Changes in Adolescent Mental Health during the COVID-19 Pandemic. Journal of Youth and Adolescence, 50, 44-57. https://doi.org/10.1007/s10964-020-01332-9

Mednick, S. (1962). The associative basis of the creative process. Psychological Review, 69(3), 220. https://doi.org/10.1037/h0048850

Mnyanyi, C. B., \& Mbwette, T. S. (2009). Open and Distance Learning in Developing Countries: The Past, the Present, and the Future. Open University of Tanzania.

Molnar, A., Miron, G., Elgeberi, N., Barbour, M. K., Huerta, L., Shafer, S. R., \& Rice, J. K. (2019). Virtual Schools in the US 2019. Boulder, CO: National Education Policy Center. http://nepc.colorado. edu/publication/virtual-schools-annual-2019. Accessed 20 Aug 2020.

Nacu, D., Martin, C. K., \& Pinkard, N. (2018). Designing for 21st century learning online: A heuristic method to enable educator learning support roles. Educational Technology Research and Development, 66(4), 1029-1049. https://doi.org/10.1007/ s11423-018-9603-0

Newell, A., \& Simon, H. A. (1972). Human problem solving. Vol. 104, No. 9. Englewood Cliffs, NJ: Prentice-hall.

Nikiforos, S., Tzanavaris, S., \& Kermanidis, K. L. (2020). Virtual learning communities (VLCs) rethinking: Collaboration between learning communities. Education and Information Technologies, 1-17. https://doi.org/10.1007/s10639-020-10132-4

Nunnally, J. (1967). Psychometric theory. McGrawHill.

Nusbaum, A. T., Cuttler, C., \& Swindell, S. (2020, January). Open educational resources as a tool for educational equity: Evidence from an introductory psychology class. In Frontiers in Education, 4, 152. Frontiers. https://doi.org/10.3389/feduc.2019.00152 
Papanastasiou, E., \& Papanastasiou, C. (2021). Methodology of educational research (4th edition). (In Greek)

Pelowski, M., Leder, H., \&Tinio, P. P. (2017). Creativity in the visual arts. In The Cambridge Handbook of Creativity across Domains . Cambridge University Press, pp. 80-109. https://doi.org/10.1017/ 9781316274385.006

Piaget, J. (1960). The child's concept of the word. Helix Books, Rowan.

Ramos, J. L. S., Dolipas, B. B., \& Villamor, B. B. (2013). Higher order thinking skills and academic performance in physics of college students: A regression analysis. International Journal of Innovative Interdisciplinary Research, 4(1), 48-60.

Ramirez, R., \& Bell, R. (1994). Byting Back: Policies To Support the Use of Technology in Education. https://files.eric.ed.gov/fulltext/ ED378941.pdf. Accessed 1 Sept 2021.

Rau, W., \& Durand, A. (2000). The academic ethic and college grades: Does hard work help students to" make the grade"? Sociology of Education, 73(1), 19-38. https://doi.org/10.2307/2673197

Rodgers, T. (2008). Student engagement in the e-learning process and the impact on their grades. International Journal of Cyber Society and Education, 1(2), 143-156. https://www.learntechlib.org/p/ 209167/. Accessed 25 Aug 2020.

Roussos, L. P., \& Tsaousis, G. (2011). Applied Statistics in Social Sciences. Ellinika Grammata. (In Greek).

Rovai, A. P. (2002). Sense of community, perceived cognitive learning, and persistence in asynchronous learning networks. The Internet and Higher Education, 5(4), 319-332. https://doi.org/10.1016/ S1096-7516(02)00130-6

Sawyer, R. K. (2011). Explaining creativity: The science of human innovation. Oxford University Press.

Stahl, G., Koschmann, T., \& Suthers, D. (2006). Computer-supported collaborative learning: An historical perspective. In R. K. Sawyer
(Ed.), Cambridge handbook of the learning sciences (pp. 409426). Cambridge University Press.

Thamarana, S. (2016). Role of e-learning and virtual learning environment in english language learning. In Reddi Sekhar Reddy, G. \& Manjula, R. (Eds.), Teaching English Language and Literature: Innovative Methods and Practices. Research India press.

Tinio, P. P. (2013). From artistic creation to aesthetic reception: The mirror model of art. Psychology of Aesthetics, Creativity, and the Arts, 7(3), 265. https://doi.org/10.1037/a0030872

Veermans, M., \& Cesareni, D. (2005). The nature of the discourse in web-based collaborative learning environments: Case studies from four different countries. Computers \& Education, 45(3), 316-336. https://doi.org/10.1016/j.compedu.2005.04.011

Wells, G. (2002). The role of dialogue in activity theory. Mind, Culture, and Activity, 9(1), 43-66. https://doi.org/10.1207/S15327884M CA0901_04

Wheeler, S., \& Wheeler, D. (2009). Using wikis to promote quality learning in teacher training. Learning, Media and Technology, 34(1), 1-10. https://doi.org/10.1080/17439880902759851

Zhang, L. F., \& Sternberg, R. J. (2011). Revisiting the investment theory of creativity. Creativity Research Journal, 23(3), 229-238. https://doi.org/10.1080/10400419.2011.595974

Publisher's note Springer Nature remains neutral with regard to jurisdictional claims in published maps and institutional affiliations. 